\title{
The Economic Value of Changes in Harvest Regulations to Anglers on Charter and Private Boat Trips: Results from a Choice Experiment Survey in Southeastern U.S. Waters
}

\author{
CHRISTOPHER LIESE and DAVID W. CARTER
}

\section{Introduction}

U.S. law mandates that NOAA's National Marine Fisheries Service (NMFS) consider the anticipated changes in economic value when promulgating new marine fishing regulations. NMFS has used information on anglers' value or willingness to pay (WTP) for catching and keeping fish, derived from stated preference choice experiments (SPCE) or travel cost methods, to measure changes in economic value to the recreational sector.

In this paper, we use a multispecies SPCE with varying levels of bag limits to update estimates of the WTP for marine recreational fishing in the U.S. southeast. Notably, our choice experiment values regulations - not catching or keeping of fish. Others (Carter and Liese, 2012; Lew and Larson, 2014, 2015) use choice experiments that feature regulations. However, these studies also include the expected catch

The authors are with the Southeast Fisheries Science Center, National Marine Fisheries Service, NOAA, 75 Virginia Beach Drive, Miami, FL 33149 (christopher.liese@noaa.gov).

doi: https://doi.org/10.7755/MFR.79.3-4.1 among trip attributes in the SPCE. In our approach, the choice situation faced by respondents in our survey more closely reflects the actual choice situation prior to a fishing trip, where regulations are known but fishing success is not.

Our SPCE modeling also explicitly considers how angler values might vary over the range of potential bag limits, including zero which represents the case when the fishing season is closed. Much of the research on angler preferences assumes that the relationship between angler WTP and catching or keeping fish is linear or other simple function. A constant marginal WTP, i.e., a non-decreasing marginal WTP, is convenient for regulatory analysis, but, if incorrect, could lead to inaccurate estimates of changes in economic value.

Furthermore, anglers' value for regulations and catching or keeping fish might change in discrete ways that are crucial to consider in economic analyses. Anglers might place a large value on the opportunity to keep at least one fish, but value subsequently kept fish relatively less or not at all.

We refer to the case where the angler does not value subsequently kept fish after the first as "open season" preference or specification. For many species, anglers may not expect to catch a large number of fish (if any) so that simply having the option to harvest one fish (per angler on the boat) is the main determinant of value on any given day of fishing.

Another goal of this research is to determine whether anglers' preferences for bag limits depends on how they fish. Specifically, little is known about whether anglers fishing on charter vessels share the same underlying preferences as other recreational anglers. There is considerable research on the preferences of anglers fishing from private boats or from the shore (Johnston et al., 2006). Less research has been conducted on the preferences of anglers fishing from charter boats (Poor and Breece, 2006; Whitehead et al., 2011; Lew and Larson, 2012, 2014, 2015). ${ }^{1}$

Only Lew and Larson (2014) present separate charter and private boat WTP estimates for anglers from the

${ }^{1}$ Anderson and Lee (2013) and Anderson, Lee, and Levin (2013) include charter and private boat choice experiment questions, but they do not generate separate value estimates for charter and private boat fishing.
ABSTRACT-We estimate the economic value of changes in saltwater fishing regulations to anglers fishing on charter and private boat trips in southeastern U.S. waters. Our new estimates of angler willingness to pay (WTP) are for hypothetical changes in the bag limits for dolphinfish, Coryphaena hippurus; red snapper, Lutjanus campechanus; other/aggregate snappers, Lutjanidae spp.; grouper, Epinephelus spp. and Mycteroperca spp.; and king mackerel, Scomberomorus cavalla. We use a multispecies choice experiment with varying levels of regulations (e.g., bag limits), not catching or keeping fish. The focus on changes in regulations, instead of catch, allows us to explicitly consider how angler WTP might vary over the range of potential regulation levels, including closure.

We compare three specifications of WTP for regulations that span the range of economically reasonable behavior: no decreasing marginal WTP (linear increasing $W T P)$, piece-wise linear WTP, and absolute decreasing marginal WTP, where only the first unit has value (i.e., anglers care about the opening of the season but not about how many fish they may keep). We find $a b-$ solute decreasing marginal WTP for four out of the five cases we can evaluate. We also test whether the WTP for regulations depends on the mode of fishing (charter or private boat). After controlling for differences in party size, we find no statistical evidence that the WTP differs between the two modes. 
same underlying population (residents fishing in southcentral Alaska). They do not formally test whether the comparable WTP estimates for charter boat fishing are different from the WTP estimates for private boat fishing. However, the confidence intervals on the WTP estimates for charter and private boat fishing overlap.

We generate separate estimates of the value of bag limits to anglers fishing on charter boats and private boats and formally compare the estimates. It is important to consider any differences in angler value between charter and private boat fishing modes in economic analyses, especially in cases where different regulations are proposed for each mode.

Beyond the conceptual, a central objective of this paper is to report new estimates of saltwater anglers' WTP for changes in regulations for dolphinfish, Coryphaena hippurus; red snapper, Lutjanus campechanus; other snappers, Lutjanidae spp.; grouper, Epinephelus spp. and Mycteroperca spp.; and king mackerel, Scomberomorus cavalla, on charter and private boat trips in southeastern U.S. waters. We start by examining, for each type of trip (charter or private) and for each species, how the WTP varies over a range of possible bag limit changes. Specifically, we test whether the relationship between WTP and bag limits is linear, non-linear, or discrete, whereby anglers are willing to pay to open the fishery but not for subsequent increases in the bag limit (open season specification). We use a piecewise-linear (PWL) specification for our non-linear modeling of WTP over bag limits because this is the most general specification given the set-up of our SPCE. The PWL specification is commonly used as a general way to model preferences over attributes in choice experiments (Layton and Brown, 2000; Siikamäki and Layton, 2007).

Then, using the best fitting model for each type of trip, we compare the WTP estimates for fishing on charter and private boat trips with each other and estimates from the literature. We conduct the analysis using data from a choice experiment conducted with a mail survey of anglers intercepted on fishing trips in southeastern U.S. waters.

\section{Materials and Methods}

\section{Data Collection and Experimental Design}

Addresses were collected from willing anglers who were intercepted during or after shore, private boat, or charter boat fishing trips during the 2009 Marine Recreational Information Program (MRIP) access point survey in North Carolina, South Carolina, and Georgia. Any intercepted angler who had taken a charter fishing trip in the previous 12 months and agreed to participate was mailed the South Atlantic Charter Fishing Survey (charter survey). Anglers intercepted on a private boat trip who did not take a charter fishing trip in the previous 12 months, but who agreed to participate, were mailed the South Atlantic Sportfishing Survey (private boat survey). Both surveys consisted of 16 pages of questions about recreational fishing experience and recent activity, preferences for different types of fishing trips, and household characteristics.

The survey instruments were designed with the input of charter captains and recreational anglers. We conducted informal interviews with charter captains at regional marinas before creating the surveys and tested preliminary survey instruments with a series of focus groups. Two focus groups were held with charter captains and two focus groups were held with recreational anglers in locations along the U.S. South Atlantic coast.

There were 15,638 MRIP angler intercept interviews between March and December of 2009 in North Carolina, South Carolina, and Georgia where anglers were asked if they would participate in a follow-up mail survey. Of the 2,277 anglers (15\%) who agreed to the follow-up mail survey, 1,537 were sent the charter boat version and 740 were sent the private boat version. There were 805 (52\%) charter boat surveys returned and 440 (59\%) pri- vate boat surveys returned. We oversampled with the charter boat version because of the difficulty of finding anglers with relevant charter boat experience via the MRIP.

Indeed, upon further inspection, only 485 of the 805 returned charter boat surveys included valid responses completed by anglers with some charter boat fishing experience in the southeastern U.S. marine waters (as determined by supporting questions on the survey instrument). By comparison, 373 of the 440 returned private boat surveys had valid responses completed by anglers with private boat experience in the region.

Summary statistics for the anglers who returned usable charter and private boat surveys, respectively, are shown in Table 1. These variables are not used in the model but are presented here as background on the type of anglers included in the surveys. All differences, except age and familiarity with federal regulations, are statistically different based on a t-test.

Anglers who took the charter and private boat surveys are similar in terms of gender, age, and fishing experience. Those who took the charter survey earned slightly more income and were less likely to have a saltwater fishing license. This latter difference is expected, given that a license is not required to fish on a charter vessel, and many of these anglers were intercepted after a charter trip. Similarly, those who took the private-boat survey were recruited after taking a private boat trip, so ownership of both a fishing permit and boat are more likely. In both cases, less than half of the anglers reported being familiar with saltwater fishing regulations in the federal waters of the U.S. southeast.

The charter and private boat surveys each had choice experiment (CE) questions designed to elicit preferences for trip characteristics or attributes (fee, duration, regulations, etc.). Following Oh et al. (2005) and Carter and Liese (2012), the CE questions asked respondents to choose their preferred trip from two hypothetical fishing trips that differ by attribute levels. 
Table 1.-Summary statistics for selected variables describing the anglers who were intercepted in 2009 by the Marine Recreational Fishing Statistic Survey in North Carolina, South Carolina, or Georgia, and a) were on any type of fishing trip, had taken a saltwater charter fishing trip in the previous year, and completed the South Atlantic Charter Fishing Survey or b) were on a private boat, did not take a charter fishing trip in the previous year, and completed the South Atlantic Saltwater Sportfishing Survey.

\begin{tabular}{|c|c|c|c|c|c|c|}
\hline Variable & Responses & Mean & Std. Dev. & Median & Min & Max \\
\hline \multicolumn{7}{|l|}{ Completed the Charter Fishing Survey $(n=485)$} \\
\hline Male (\%) & 481 & $93 \%$ & 0.26 & & & \\
\hline Age & 481 & 50.06 & 12.88 & 51 & 20 & 73 \\
\hline Income (USD) & 461 & $\$ 109,653$ & $\$ 70,251$ & $\$ 75,000$ & $\$ 12,500$ & $\$ 300,000$ \\
\hline Experience (years) & 480 & 27.07 & 15.85 & 28 & 1 & 65 \\
\hline Boat ownership (\%) & 485 & $63 \%$ & 0.48 & & & \\
\hline Marine fish license (\%) & 485 & $83 \%$ & 0.38 & & & \\
\hline Familiar with federal regulations? (\%) & 485 & $47 \%$ & 0.50 & & & \\
\hline \multicolumn{7}{|l|}{ Completed the Sportfishing Survey $(n=373)$} \\
\hline Male (\%) & 373 & $97 \%$ & 0.18 & & & \\
\hline Age & 365 & 49.06 & 13.85 & 49 & 18 & 73 \\
\hline Income (USD) & 352 & $\$ 96,058$ & $\$ 57,138$ & $\$ 75,000$ & $\$ 12,500$ & $\$ 300,000$ \\
\hline Experience (years) & 354 & 29.96 & 16.12 & 30 & 2 & 65 \\
\hline Boat ownership (\%) & 373 & $81 \%$ & 0.39 & & & \\
\hline Marine fish license (\%) & 362 & $99 \%$ & 0.07 & & & \\
\hline Familiar with federal regulations? (\%) & 357 & $43 \%$ & 0.50 & & & \\
\hline
\end{tabular}

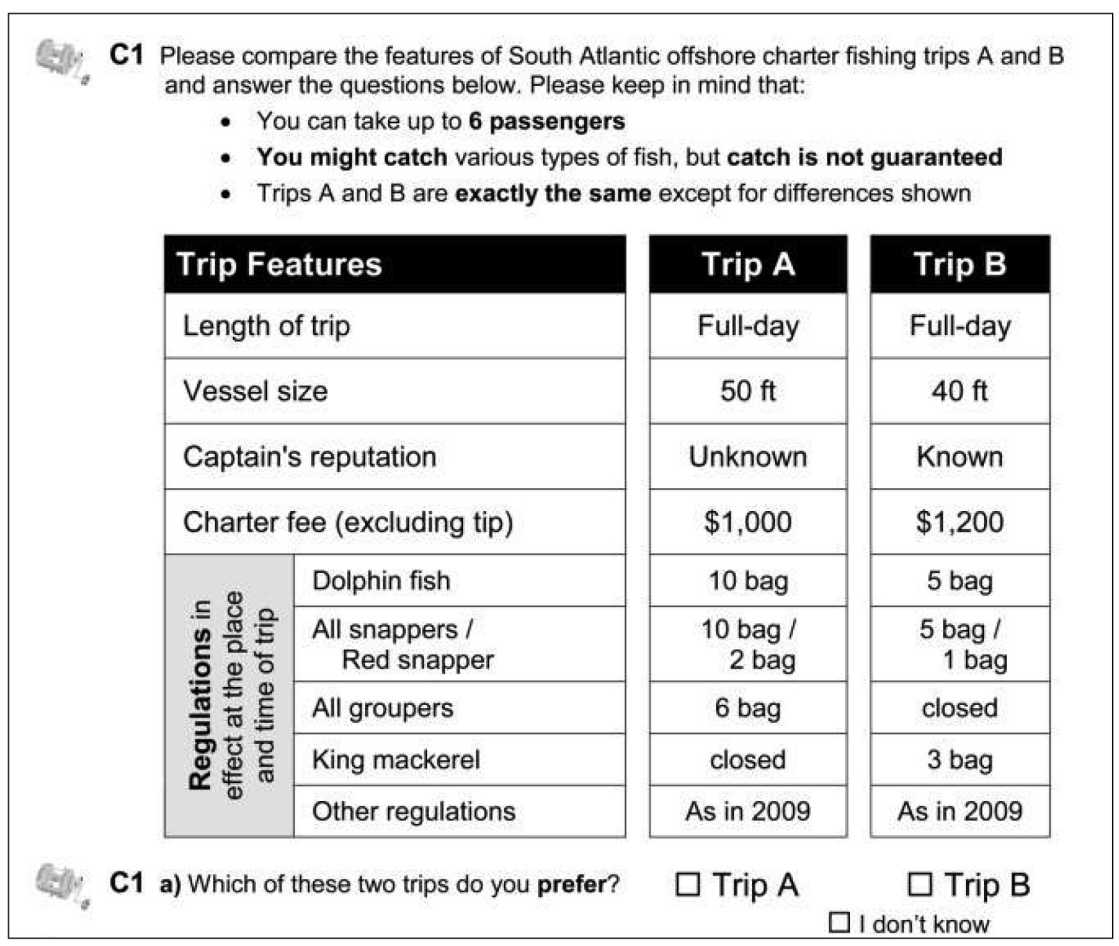

Figure 1.-Example choice question from the South Atlantic Charter Fishing Survey.

Each respondent was presented with six CE questions. The first four attributes of the $\mathrm{CE}$ questions were customized for the charter and private boat surveys (Fig. 1, 2). The charter survey contained length of trip (half or full day), vessel size (40 or 50 $\mathrm{ft}$.), captain's reputation (unknown or known), and charter fee (\$400, \$600, $\$ 800, \$ 1,000, \$ 1,200, \$ 1,400)$; whereas the private boat survey contained hours on the water ( 4 or 8 ), time of the week (weekday or weekend), bottom type of area fished (artificial or natural), and trip cost $(\$ 25, \$ 40, \$ 55, \$ 70$, \$85, \$100).
Note that the charter fee and the trip cost attributes were designed to be dependent (nested) on the length of trip and hours on the water, respectively. Specifically, the bottom three dollar levels were linked to the shorter trips, while the top three dollar levels were linked to the longer trips. With regard to captain reputation, the attribute was simply whether the captain's reputation was known or not. This could be a good or bad reputation, but in our focus groups most anglers interpreted whether or not the captain was known to have a "good" reputation. Consequently, we assume that this is how the attribute will be interpreted on average by the survey respondents.

The last five attributes in the $\mathrm{CE}$ question represent bag limit regulations for selected species in effect at the time and place of each hypothetical trip. These attributes were the same in the charter and private boat surveys. The following species and bag limit levels were selected: dolphinfish (5 bag or 10 bag), aggregate snapper ( 5 bag or 10 bag), red snapper (closed, 1 bag, 2 bag, or 3 bag), aggregate grouper (closed, 2 bag, 4 bag, or 6 bag), and king mackerel (closed, 1 bag, 2 bag, or 3 bag). ${ }^{2}$

Another attribute was listed for the level of the other regulations, but this attribute was fixed to read "as in 2009" for all trips. Respondents were asked which of the two trips they preferred. They could select "don't know," but they did not have the option to "not take a trip" because the focus of the analysis is on attribute trade-offs (preferences for trip features), not participation (the decision to take a trip). ${ }^{3}$ The experimental design for the $\mathrm{CE}$

${ }^{2}$ The actual daily bag limits in federal waters at the time of the survey were: dolphinfish-10 bag, aggregate snapper-10 bag, red snapper-2 bag, aggregate grouper-3 bag, and king mackerel-2 bag.

${ }^{3}$ Note that the choice questions explicitly asked respondents to only express their preferences among two different trip options (Fig. 1, 2). Even though we did not include the option to not take a trip (opt-out), respondents are not forced to make a choice because they could mark "don't know." Less than $5 \%$ of choices in the charter boat survey and fewer than $3 \%$ of choices in the private boat survey were marked "don't know" suggesting that respondents were 


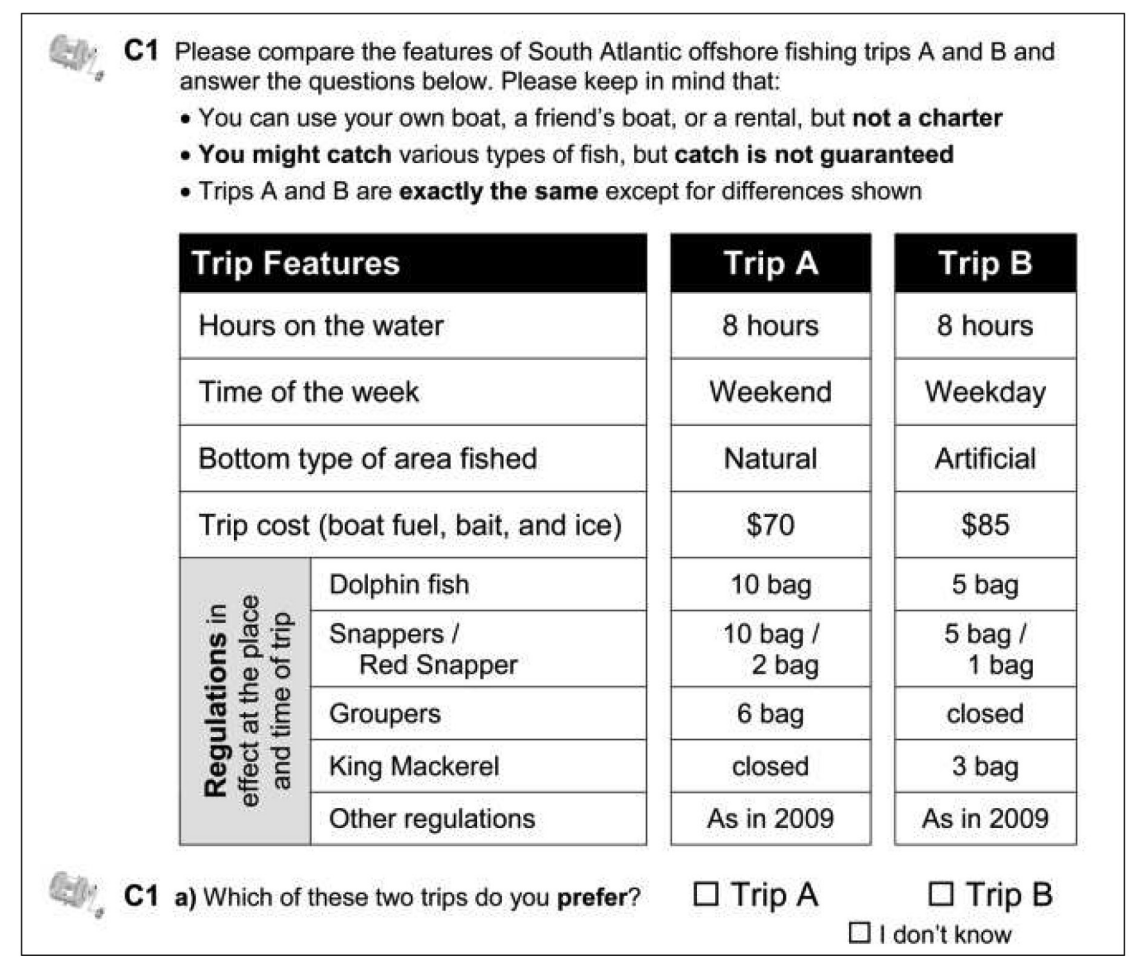

Figure 2.-Example choice question from the South Atlantic Sportfishing Survey.

questions is discussed below following the model specification and estimation section.

\section{Model Specification and Estimation}

The CE questions involved a choice between Trip A and Trip B as shown in Figure 1 and Figure 2. The choice can be modeled within a random utility framework (McFadden, 1974). Following the framework, we assume that the angler will choose the option that provides the greatest utility. However, we cannot predict with certainty the choice that a given angler will make with the information at hand. There is always some portion of the decision that we cannot observe.

In this case, the best we can do is predict the probability that an angler will choose one of the two options based on the attributes of the trips. Formally, we specify the (indirect)

comfortable declaring their preferences for the trips presented in the $\mathrm{CE}$. a $40 \mathrm{ft}$ boat; known equals 1 for a trip associated with charter trip op where fee is the charter fee for the boat; party is the number of passengers on the boat; fullday equals 1 for a full day trip and 0 for a half day trip; with a captain of known reputation and 0 for a trip with a captain of unknown reputation; dolphin 10 equals 1 for a 10 dolphinfish bag limit and 0 for a 5 dolphinfish bag limit; snapper 10 equals 1 for a 10 snapper aggregate bag limit and 0 for a 5 snapper aggregate bag limit; red 1 , red 2 , and red 3 equal 1 for a 1,2 , or 3 red snapper bag limit, respectively, and 0 otherwise; grouper 2 , grouper4, and grouper6 equal 1 for a 2,4 , or 6 aggregate grouper bag limit, respectively, and 0 otherwise; kingl, king2, and king3 equal 1 for a 1, 2, or 3 king mackerel bag limit, respectively, and 0 otherwise; $\alpha 1$ through $\alpha 15$ are the parameters to be estimated and $\varepsilon^{c}$ is an error term representing the unknown factors of the charter trip utility function. Note that the bag limit attributes enter the expression for utility as a piecewise-linear function which is the most general form possible given the set-up of the choice experiment (Layton, 2001).

Also, we assume that, on average, the charter fee for the boat is split evenly among the number of passengers. The number of passengers on each hypothetical trip was not specified in the survey. Eighty-three of the completed charter trip surveys were based on addresses collected from anglers intercepted on charter trips. The average number of passengers on these intercepted charter trips was 4.81. Therefore, we assume that "party" equals 5 for all of the hypothetical trip options specified in equation (1).

$$
\begin{aligned}
& U_{n q i}^{c}=v_{n q i}^{c}+\varepsilon_{n q i}^{c} \\
& =\alpha 1 \cdot\left(\frac{\text { fee }_{n q i}}{\text { party }_{n q i}}\right)+\alpha 2 \cdot \text { fullday }_{n q i}+\alpha 3 \cdot f t 50_{n q i}+\alpha 4 \cdot k n o w n_{n q i}
\end{aligned}
$$

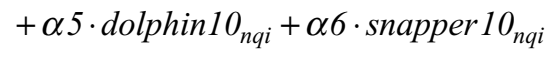

$$
\begin{aligned}
& +\alpha 7 \cdot \operatorname{red} 1_{n q i}+\alpha 8 \cdot \operatorname{red} 2_{n q i}+\alpha 9 \cdot \operatorname{red} 3_{n q i} \\
& +\alpha 10 \cdot \text { grouper } 2_{n q i}+\alpha 11 \cdot \text { grouper } 4_{n q i}+\alpha 12 \cdot \text { grouper } \sigma_{n q i} \\
& +\alpha 13 \cdot \operatorname{king} 1_{n q i}+\alpha 14 \cdot \operatorname{king} 2_{n q i}+\alpha 15 \cdot \operatorname{king} 3_{n q i} \\
& +\varepsilon_{n q i}^{c}
\end{aligned}
$$

.

.

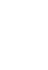

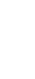

(1)

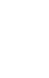

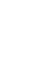

.

.

.

.

.


A similar indirect utility function is specified for private boat trip option $i$, Trip A or Trip B, for angler $n$ on choice question $q$ as

$$
\begin{aligned}
U_{n q i}^{p} & =v_{n q i}^{p}+\varepsilon_{n q i}^{p} \\
& =\beta 1 \cdot \operatorname{cost}_{n q i}+\beta 2 \cdot \text { hours } 8_{n q i}+\beta 3 \cdot \text { weekend }_{n q i}+\beta 4 \cdot \text { artificial }_{n q i} \\
& +\beta 5 \cdot \text { dolphin } 10_{n q i}+\beta 6 \cdot \text { snapper } 10_{n q i} \\
& +\beta 7 \cdot \operatorname{red} 1_{n q i}+\beta 8 \cdot \operatorname{red} 2_{n q i}+\beta 9 \cdot \operatorname{red} 3_{n q i} \\
& +\beta 10 \cdot \operatorname{grouper} 2_{n q i}+\beta 11 \cdot \operatorname{grouper} 4_{n q i}+\beta 12 \cdot \text { grouper }_{n q i} \\
& +\beta 13 \cdot \operatorname{king} 1_{n q i}+\beta 14 \cdot \operatorname{king} 2_{n q i}+\beta 15 \cdot \operatorname{king} 3_{n q i} \\
& +\varepsilon_{n q i}^{p}
\end{aligned}
$$

where cost is the trip cost per angler; hours 8 equals 1 for an 8 hour trip and 0 for a 4 hour trip; weekend equals 1 for a trip on the weekend and 0 for a trip during the week; artificial equals 1 for a trip fishing over artificial bottom and 0 for a trip fishing over natural bottom; $\beta 1$ through $\beta 15$ are the parameters to be estimated, and $\varepsilon^{p}$ is an error term representing the unknown factors of the private boat trip utility function. The bag limit attributes are as defined for equation (1).

Assuming the error terms of the charter and private boat trip utility functions are distributed as independent type-I extreme value random variables, the probability of angler $n$ on choice question $q$ selecting option $i$ (Trip A or Trip B) can be modeled as a conditional logit. For example, the conditional logit probability for the charter trip model is given by

$$
\pi_{n q i}^{c}=\frac{\exp \left(\lambda^{c} v_{n q i}^{c}\right)}{\sum_{j=1}^{2} \exp \left(\lambda^{c} v_{n q j}^{c}\right)}
$$

where $\lambda^{c}$ is a scale parameter. ${ }^{4}$ The parameters in (1) along with the parameter covariance matrix are estimated by maximizing the log-

\footnotetext{
${ }^{4}$ More complex assumptions regarding the error terms and different estimators for the final models produced qualitatively similar results to the simple conditional logit specification. The more complex specifications included estimators that allowed the error terms to be correlated across each of the respondent's six choices and estimators that allowed for correlated unobserved factors in the parameters on the regulation attributes (Train, 2009). These results are available upon request.
}

likelihood of the probability in (3). Again, continuing with the charter boat trip model example, the log-likelihood is given by

$$
\text { (4) } L L(\alpha)=\sum_{n=1}^{485} \sum_{q=1}^{Q_{n}} \sum_{i=1}^{2} y_{n q i}^{c} L n \pi_{n q i}^{c}
$$

where $y_{n q i}^{c}$ equals 1 if angler $n$ during choice question $q$ chooses alternative $i$ or 0 otherwise, $\alpha$ is the vector of fifteen parameters to be estimated, and $Q_{n}$ is the number of choice questions answered by respondent $n$ (Haab and McConnell, 2002). Note that respondents may not have answered all of the choice questions such that $Q_{n} \leq 6$. Similar expressions for the conditional logit probability, $\pi_{n q i}^{p}$, and log-likelihood, $L L(\beta)$, can be defined for the private boat model. The parameters of (1) and (2) are estimated via maximum likelihood using the "mlogit" package of R (R Core Team, 2016; Croissant, 2013).

\section{Experimental Design}

The same experimental design was used for the charter and private boat versions of the $\mathrm{CE}$ survey questions because the number and levels of the attributes were the same in each version. With one 6-level attribute, four 2-level attributes, and three 4-level attributes, the total possible types of trips based on all permutations of the attribute levels - the full factorial design-consists of $6 \cdot 16 \cdot 64=6,144$ potential trip types. In principle, over 18.8 million combinations of two trips are possible.
We used SAS software ${ }^{5}$ to generate a fractional factorial choice design from these potential trip types (Kuhfeld, 2010). Specifically, a computer algorithm was used to search over the 6,144 potential trip types for 96 pairs of trips (choice sets) that minimized the variance of the logit in (3) conditional on an assumed parameter vector (Ferrini and Scarpa, 2007). However, for the purposes of the experimental choice design algorithm we expanded the angler utility function in equation (1) to include interactions of between trip duration and continuous versions of the non-cost attributes.

The parameters on the first three binary attributes (fullday, 50ft, and known in the charter model) were assumed to be $3,0.5$, and 1, respectively, and the parameter on cost was assumed to be -1. All other parameters were fixed at zero in the experimental choice design algorithm. A design with 96 choice sets is too large to show to each angler. Therefore, the design was separated into 16 choice set blocks, and each angler only saw one block of 6 choice sets. Another SAS software algorithm from Kuhfeld (2010) was used to create the blocking factor to be (nearly) uncorrelated with every attribute of both alternatives.

\section{Specification Tests and Model Comparisons}

The utility functions for charter and private boat trips shown in (1) and (2) are PWL in the regulations for species with more than 2 levels, i.e., red snapper, grouper, and king mackerel. This is the most general way the regulation variables can enter the utility function. However, angler utility and related WTP might be influenced by regulations in a less complex way.

We consider two additional possibilities. First, the regulations could enter the utility function linearly such that the incremental change from one regulation level to the next is constant or non-decreasing, e.g., the first fish is

${ }^{5}$ Mention of trade names of commercial firms does not imply endorsement by the National Marine Fisheries Service, NOAA. 
Table 2.-Potential restrictions in the charter boat model.

\begin{tabular}{lcc}
\hline Species & \multicolumn{1}{c}{ Linear } & Open season \\
\hline Red snapper & $\alpha 7=\alpha 8 / 2=\alpha 9 / 3$ & $\alpha 7=\alpha 8=\alpha 9$ \\
Grouper & $\alpha 10 / 2=\alpha 11 / 4=\alpha 12 / 6$ & $\alpha 10=\alpha 11=\alpha 12$ \\
King mackerel & $\alpha 13=\alpha 14 / 2=\alpha 15 / 3$ & $\alpha 13=\alpha 14=\alpha 15$ \\
\hline
\end{tabular}

valued the same as the fifth. The linear specification is commonly assumed in sportfishing valuation models. Second, anglers could be willing to pay for an open season, but no additional amount for higher bag limits. These two specifications contain the range of economically reasonable behavior: no decreasing marginal returns to absolute decreasing marginal returns where only the first unit has value.

The parameter restrictions for the charter boat model (1) implied by the linear and open season specifications are summarized in Table 2. The same restrictions apply to the private boat model with $\beta$ in place of $\alpha$ in the table. We evaluate the plausibility of each restriction for each species by plotting the regulation parameters of the PWL model. Based on the plots we specify a parsimonious model for each trip type that incorporates the plausible set of restrictions suggested by the parameter plots. A likelihood ratio test is used to determine whether the more parsimonious functional relationships between utility and the regulations fits the data at least as well as the PWL specification.

The parameters in (1) and (2) measure the relative angler utility or value associated with each attribute on charter and private boat trips. However, the estimated parameters cannot be directly compared between the charter and private boat models because the models might have different values for the scale parameter (Swait and Louviere, 1993). Dividing each coefficient in each model by the respective coefficient on the trip cost attribute, $\beta 1$ or $\alpha 1$, removes the scale and measures the amount of money that a representative angler would be willing to pay to make him or her indifferent to a one unit increase in an attribute (Bockstael and McConnell, 2007). This measure of angler WTP can be compared between the charter and private boat models.

We calculate the confidence intervals for the parameter ratios for each WTP measure using the approach introduced by Krinsky and Robb (1986) and shown to be an accurate method for WTP measures by Hole (2007). We use 10,000 replications in the KrinskyRobb method. The simulated WTP vectors based on the 10,000 replications can also be used in the method of convolutions to test the hypothesis that the regulation WTP estimates are the same on charter and private boat trips (Poe et al., 2005). We use the "mded" package in $\mathrm{R}$ to perform the hypothesis tests using the method of convolutions (Aizaki, 2015; R Core Team, 2016).

\section{Results \\ Piecewise-Linear Models and Specification Tests}

The maximum likelihood parameter estimates of the PWL conditional logit model parameters are shown in Table 3 for the charter and private boat trip models. The means and confidence intervals for the WTP for each attribute are shown in the last 3 columns of the table. At the maximum, the log likelihood value for the charter boat trip model is -1750.5 which compares with a $\log$ likelihood of -1911.4 for a null model that only includes a constant for the Trip B option. A likelihood ratio test $\left(2 \cdot(1911.4-1750.5)=321.8 \sim \chi^{2}\right.$, $14 \mathrm{df})$ rejects the hypothesis that these 2 log likelihoods are equal and indicates that the model as specified fits better than the null model. Similarly, the log likelihood value for the private boat trip model is -1404.3 compared with a log likelihood of -1500.1 for a null model. Again, the likelihood ratio test suggests that the specified private boat model fits better than the null model $(2 \cdot(1500.1-1404.3)=191.6 \sim$ $\left.\chi^{2}, 14 \mathrm{df}\right)$.

As we would expect, anglers are less likely to choose higher cost charter trips, and more likely to choose fullday trips, trips on larger boats, and trips with captains of known reputation. Specifically, full day charter trips are valued at $\$ 90$ more per person than half-day trips on average, and anglers are willing to pay $\$ 72$ per person more on average for trips where the captain's reputation is known than for trips where the captain's reputation is unknown.

The size of the charter vessel is less important, but anglers are still willing to pay $\$ 11$ per person extra on average to fish on a 50-foot vessel instead of a 40-foot vessel. Anglers on private boats are also less likely to choose higher cost private boat trips. However, the other nonregulation private trip attributes are not statistically different from zero even at the $10 \%$ significance level.

Higher dolphinfish and aggregate snapper bag limits increase the likelihood of a trip being chosen in both charter and private boat trip models. Anglers are willing to pay $\$ 17$ and $\$ 13$ more per person for a 10 -fish instead of 5-fish dolphinfish bag limit on charter and private trips, respectively. This amounts to an average of $\$ 3.40$ per dolphinfish on charter trips and $\$ 2.60$ per dolphinfish on private boat trips. Similarly, anglers are willing to pay $\$ 11$ and $\$ 8$ per person more for a 10-fish instead of 5-fish aggregate snapper bag limit on charter and private trips, respectively. This is an average of $\$ 2.20$ and $\$ 1.60$ per snapper on charter and private boat trips, respectively.

We now turn to the results for parameters on the regulations for red snapper, aggregate grouper, and king mackerel which each had four bag limit levels, including zero which would correspond to a closed season. The discussion will make use of Figure 3 and 4 which plot the mean total and incremental WTP for bag limits from the PWL models (charter and private) for each species. We have drawn the 
Table 3.-Parameter and willingness-to-pay (WTP) estimates from the piecewise-linear conditional logit trip choice models for charter and private boat trips. The lower bound (LB) and upper bound (UB) of the 95 percent confidence intervals for the WTP estimates are generated using the Krinsky and Robb (1986) method with 10,000 draws.

\begin{tabular}{|c|c|c|c|c|c|c|c|}
\hline \multirow[b]{2}{*}{ Attribute } & \multirow[b]{2}{*}{ Parameter } & \multirow[b]{2}{*}{ Estimate } & \multirow[b]{2}{*}{ Std. error } & \multirow[b]{2}{*}{$P$-value } & \multicolumn{3}{|c|}{ WTP (2009 \$) } \\
\hline & & & & & LB & Mean & UB \\
\hline \multicolumn{8}{|c|}{ Charter trips model (485 respondents, 2,758 choices, LL = -1751) } \\
\hline fee/party & $\alpha 1$ & -0.015 & 0.002 & 0.000 & & & \\
\hline fullday & $\alpha 2$ & 1.309 & 0.277 & 0.000 & 72 & 90 & 102 \\
\hline$f t 50$ & $\alpha 3$ & 0.161 & 0.062 & 0.009 & 3 & 11 & 17 \\
\hline known & $\alpha 4$ & 1.039 & 0.102 & 0.000 & 63 & 72 & 86 \\
\hline dolphin10 & $\alpha 5$ & 0.244 & 0.044 & 0.000 & 10 & 17 & 27 \\
\hline snapper10 & $\alpha 6$ & 0.154 & 0.043 & 0.000 & 5 & 11 & 19 \\
\hline red1 & $\alpha 7$ & 0.150 & 0.071 & 0.035 & 1 & 10 & 22 \\
\hline red2 & $\alpha 8$ & 0.149 & 0.071 & 0.035 & 1 & 10 & 22 \\
\hline red3 & $\alpha 9$ & 0.152 & 0.062 & 0.014 & 2 & 10 & 21 \\
\hline grouper2 & $\alpha 10$ & 0.196 & 0.073 & 0.007 & 4 & 14 & 26 \\
\hline grouper4 & $\alpha 11$ & 0.348 & 0.073 & 0.000 & 13 & 24 & 39 \\
\hline grouper6 & $\alpha 12$ & 0.509 & 0.062 & 0.000 & 24 & 35 & 52 \\
\hline king1 & $\alpha 13$ & 0.138 & 0.075 & 0.065 & 0 & 9 & 21 \\
\hline king2 & $\alpha 14$ & 0.162 & 0.071 & 0.023 & 1 & 11 & 23 \\
\hline king3 & $\alpha 15$ & 0.195 & 0.061 & 0.001 & 5 & 13 & 24 \\
\hline \multicolumn{8}{|c|}{ Private boat trip model ( 373 respondents, 2,165 choices, $L L=-1404$ ) } \\
\hline cost & $\beta 1$ & -0.019 & 0.007 & 0.004 & & & \\
\hline hours8 & $\beta 2$ & 0.445 & 0.309 & 0.150 & -26 & 24 & 36 \\
\hline weekend & $\beta 3$ & -0.101 & 0.069 & 0.141 & -34 & -5 & 1 \\
\hline artificial & $\beta 4$ & -0.002 & 0.110 & 0.985 & -35 & 0 & 7 \\
\hline dolphin10 & $\beta 5$ & 0.242 & 0.048 & 0.000 & 6 & 13 & 42 \\
\hline snapper10 & $\beta 6$ & 0.155 & 0.048 & 0.001 & 3 & 8 & 28 \\
\hline red1 & $\beta 7$ & -0.012 & 0.080 & 0.880 & -13 & -1 & 11 \\
\hline red2 & $\beta 8$ & 0.098 & 0.080 & 0.221 & -4 & 5 & 23 \\
\hline red3 & $\beta 9$ & -0.085 & 0.068 & 0.213 & -19 & -5 & 3 \\
\hline grouper2 & $\beta 10$ & 0.546 & 0.082 & 0.000 & 15 & 29 & 92 \\
\hline grouper4 & $\beta 11$ & 0.448 & 0.083 & 0.000 & 12 & 24 & 79 \\
\hline grouper6 & $\beta 12$ & 0.438 & 0.070 & 0.000 & 12 & 23 & 75 \\
\hline king1 & $\beta 13$ & 0.202 & 0.083 & 0.015 & 2 & 11 & 37 \\
\hline king2 & $\beta 14$ & 0.226 & 0.080 & 0.005 & 3 & 12 & 40 \\
\hline king3 & $\beta 15$ & 0.238 & 0.068 & 0.000 & 5 & 13 & 42 \\
\hline
\end{tabular}
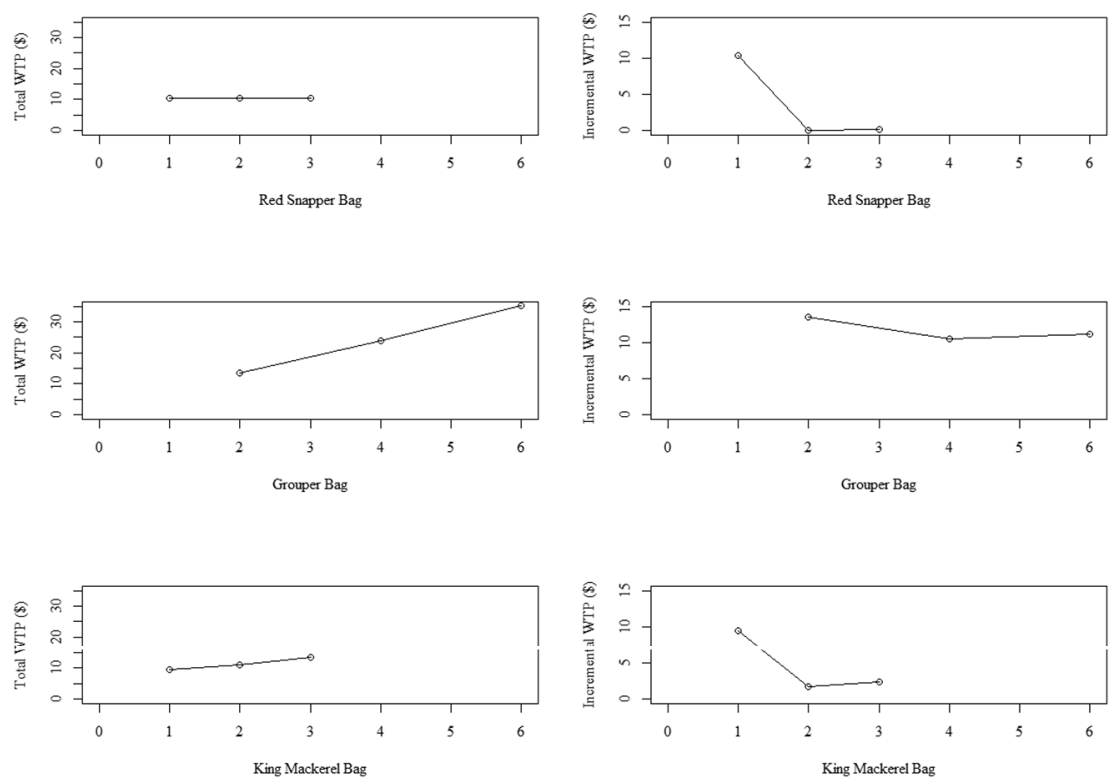

Figure 3.- Total and incremental willingness-to-pay (WTP) for bag limits on charter boat trips. figures for each species on the same scale for consistency, with the exception of incremental WTP for red snapper and groupers on a private boat trip (which include negative values).

For charter trips, angler utility parameters on all levels of the red snapper bag limits are very similar. Anglers are willing to pay $\$ 10$ on average to open the red snapper season, i.e., for a 1-fish bag limit, but not willing to pay any additional amounts for further increases in the bag limit. This shape is illustrated in the top two panels of Figure 3 and corresponds to the open season restriction in Table 2 for red snapper. For private boat trips, the parameters for red snapper bag limits are not significantly different from 0 , hence these anglers do not assign any value to the option to harvest red snapper. The first row of plots in Figure 4 show the nonsensical shape of the total and incremental WTP for red snapper bag limits on private trips. Rather than drop red snapper bag limits, we proceed with the open season restriction for the specification of the private boat model.

The parameters on the aggregate grouper bag limits and the corresponding WTP estimates for charter trips in Table 3 are statistically significant and very different from each other. However, angler WTP is similar for each 2-fish increment in the grouper bag limit. Anglers are willing to pay \$14 on average to open the grouper fishery with a 2-fish bag limit, i.e., to be allowed to keep 2 groupers on charter trips. A third and fourth allowed fish in the aggregate grouper bag are valued together at $\$ 10(\$ 24-\$ 14)$, and the fifth and sixth fish in the bag are valued at \$11 (\$35-\$24). Again, these incremental values are close, suggesting that the linear model restrictions from Table 2 may be appropriate in this case. The linear relationship between WTP and the grouper bag limit on charter trips is apparent in the second row of plots in Figure 3.

On private boat trips, the parameters and WTP estimates for each level of the grouper bag limit are similar to each other. Specifically, anglers 

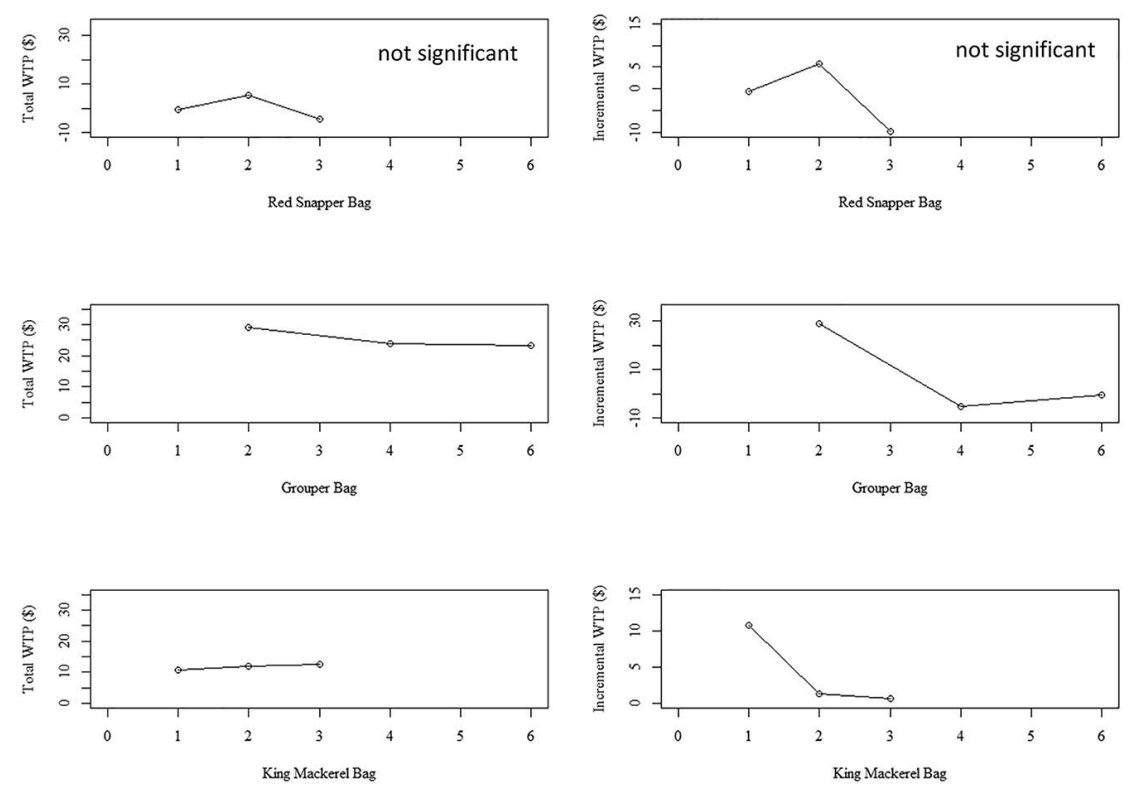

Figure 4.-Total and incremental willingness-to-pay (WTP) for bag limits on private boat trips. on private boat trips are willing to pay $\$ 29$ on average to open the grouper fishery with a 2-fish bag limit, but are not willing to pay additional amounts for further increases in the bag limit. The plots for grouper in Figure 4 (second row) further suggest that the open-season restrictions from Table 2 are appropriate for the grouper bag limit on private boat trips. Strictly speaking, the values are negative 5 and negative 1 which are not consistent with economic behavior.

Anglers on charter trips are willing to pay $\$ 9$ per person for a 1-fish bag limit of king mackerel, and \$11 and $\$ 13$, for a bag limit of 2 and 3 king mackerel, respectively. This implies an incremental WTP per person for the first, second, and third fish in the king mackerel bag limit of $\$ 10, \$ 2$, and $\$ 2$, respectively. Given the similar magnitude of WTP for the first, second, and third king mackerel bag limits, and the plots in Figure 3 (third row), we assume that the open season restrictions from Table 2 are appropriate for king mackerel on charter boat trips.

The king mackerel bag limit utility parameters appear similar for anglers on private trips and the WTP estimates are very close at $\$ 11, \$ 12$, and $\$ 13$ for 1,2 , and 3 fish bag limits, respectively. Based on the similarity of WTP over the range of king mackerel bag limits and the shape of the plots in Figure 4 (third row), we assume that the open season restrictions from Table 2 are appropriate for king mackerel on private boat trips.

\section{Parsimonious Models and WTP on Charter and Private Boats}

The regression results for the PWL model and the foregoing discussion suggest the following parsimonious expression for the charter trip utility function: 


$$
\begin{aligned}
& U_{n q i}^{c^{\prime}}=v_{n q i}^{c^{\prime}}+\varepsilon_{n q i}^{c} \\
& =\alpha I^{\prime} \cdot\left(\frac{\text { fee }_{n q i}}{\text { party }_{n q i}}\right)+\alpha 2^{\prime} \cdot \text { fullday }_{n q i}+\alpha 3^{\prime} \cdot f t 50_{n q i}+\alpha 4^{\prime} \cdot k n o w n_{n q i}
\end{aligned}
$$

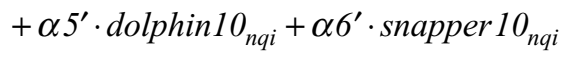

$$
\begin{aligned}
& +\alpha 7^{\prime} \cdot \text { redOpen }_{n q i}+\alpha 8^{\prime} \cdot \text { grouperBag }_{n q i} \\
& +\alpha 9^{\prime} \cdot \text { kingOpen }_{n q i}+\varepsilon_{n q i}^{c}
\end{aligned}
$$

where redOpen $=($ red $1+$ red $2+$ red 3$)$, grouperBag $=(2 \cdot$ grouper $2+4 \cdot$ grouper4 $+6 \cdot$ grouper6), and kingOpen $=$ (king1 + king2 + king3). In this model, redOpen (kingOpen) is 1 when the red snapper (king mackerel) bag limit is 1 , 2 , or 3 and is 0 for a red snapper (king mackerel) closed season; and the grouper bag limits enter linearly. Similarly, the utility function on private boat trips can be simplified as follows:

$$
\begin{aligned}
& U_{n q i}^{p^{\prime}}=v_{n q i}^{p^{\prime}}+\varepsilon_{n q i}^{p} \\
& =\beta 1^{\prime} \cdot \operatorname{cost}_{n q i}+\beta 2^{\prime} \cdot \text { hours }_{n q i}+\beta 3^{\prime} \cdot \text { weekend }_{n q i}+\beta 4^{\prime} \cdot \text { artificial }_{n q i} \\
& +\beta 5^{\prime} \cdot \text { dolphin } 10_{n q i}+\beta 6^{\prime} \cdot \text { snapper } 10_{n q i} \\
& +\beta 7^{\prime} \cdot \text { redOpen }_{n q i}+\beta 8^{\prime} \cdot \text { grouperOpen }_{n q i} \\
& +\beta 9^{\prime} \cdot \text { kingOpen }_{n q i}+\varepsilon_{n q i}^{p}
\end{aligned}
$$

where grouperOpen $=($ grouper $2+$ grouper4 + grouper6). This specification effectively has 3 binary variables, redOpen, grouperOpen, and kingOpen, for the regulations that equal 1 when fishing for red snapper, grouper, or king mackerel is open and 0 otherwise. Note that we chose to include red snapper in the parsimonious model for private boat trips despite the fact that none of the parameters on the bag limits for this species were statistically significant different from 0 in the PWL model.

The estimated utility parameters and WTP for the parsimonious models are shown in Table 4. Likelihood ratio tests cannot reject the null hypothesis that the parsimonious models fit the same as the PWL models for anglers on charter trips (2.)(1750.9 $\left.-1750.5)=0.80 \sim \chi^{2}, 6 \mathrm{df}\right)$ and private boat trips $(2 \cdot(1408.0-1404.3)=$ $\left.7.40 \sim \chi^{2}, 6 \mathrm{df}\right)$. The estimates of WTP for the second through sixth attribute in the parsimonious charter trip model reported in Table 4 are almost identical to the WTP estimates for the same attributes from the PWL charter trip model reported in Table 3. The parsimonious specification (Table 4) for the private trip model also generates WTP estimates that are similar to the PWL specification (Table 3) for the second through sixth attribute.

The results from the parsimonious charter model imply that anglers on charter trips are willing to pay $\$ 11$ and $\$ 12$, respectively, to open the red snapper season and king mackerel season regardless of the bag limits available. Anglers on charter trips are also willing to pay $\$ 6$ for each fish allowed by the grouper bag limit. In this case opening the grouper season is worth $\$ 6$ with a 1 -fish bag, $\$ 12$ with a 2 -fish bag, $\$ 18$ with a 3 -fish bag, and so on.

The results from the parsimonious private boat model suggest that anglers on private boat trips are willing to pay $\$ 24$ and \$12, respectively, to open the grouper and king mackerel seasons regardless of the bag limit available. Anglers on private boat trips in our experiment are not willing to pay anything (different than zero) on average to open the red snapper season with any of the bag limit levels presented in the survey.

The specification of the regulations for dolphinfish, snapper, and king mackerel is the same in the parsimonious charter and private boat models. Therefore, we can test the hypotheses that the WTP for regulations on these species are the same on charter and private boats. Based on the results of the method of convolutions tests, these hypotheses cannot be rejected for any of the species. Specifically, the probabilities ( $p$-values) of rejecting the null hypotheses of equality across mode is $0.292,0.318$, and 0.512 , respectively, for dolphinfish, snapper, and king mackerel.

\section{Discussion}

This paper reported on an analysis of a choice experiment survey of saltwater anglers fishing from North Carolina, South Carolina, and Georgia. We used the survey results to estimate how much anglers fishing on charter and private boats are willing to pay for changes in regulations for dolphinfish, red snapper, other snappers, groupers, and king mackerel. This information is needed to evaluate the economic effects of regulation changes proposed in fishery management plan amendments.

Unlike most previous studies, we value the regulations directly, in our case bag limits, rather than valuing the keeping of fish. This represents a shift in perspective from effectively measuring angler values "after the trip" to "before the trip," when uncertainty about actual catch still prevails.

We find that our approach generates feasible and sensible results. The approach allows for a fully multispecies choice situation, where one species (regulatory) availability is traded-off against that of other species by the respondent. Individual species availability can hence be set to zero (fishing 
closed) without making the experiment nonsensical. As a result, we can evaluate the incremental value of bag limits, starting with the first fish. This allows us to compare three specifications of preferences that span the range of economically reasonable behavior: no decreasing marginal WTP (linear increasing WTP), piece-wise linear WTP, and absolute decreasing marginal WTP, where only the first unit (i.e., opening the season) has value.

Qualitatively, for the anglers and species evaluated, we find absolute decreasing marginal WTP for four out of the five cases we can evaluate. For all cases, except grouper by charter anglers, we find that anglers are willing to pay to open the fishery but not willing to pay anything for subsequent increases in the bag limit. At first glance this finding could be interpreted to imply that opening the season with a one fish bag limit for key species will satisfy anglers. However, our results apply to preferences averaged over all types of anglers suggesting that a one fish bag limit might be acceptable on average.

Some groups, particularly expert anglers, will be willing to pay to increase the bag limit beyond one fish. More research is necessary to understand the distribution of angler preferences over the range of regulations considered in our analysis. Such findings could help managers tailor policies to reflect the preferences of specific angler groups (e.g., experts vs. novices) and potentially increase the economic value of the fisheries.

Quantitatively, the estimates of angler WTP for changes in bag limits are similar to the few comparable estimates available in other studies. Comparable estimates are those that focus on the value of changes in saltwater fishing regulations, especially in the U.S. southeast. ${ }^{6}$ Recently, Whitehead

${ }^{6}$ This does not include the literature that values changes in harvest rates (Carter and Liese, 2012, provide a recent review), i.e., the literature that values the changes in harvest rates expected to occur with changes in regulations rather than the change in the regulation itself. The value of changes in harvest will typically be higher than the value of changes in regulations on any et al. (2011) estimated that anglers fishing on charter boats in North Carolina in 2007 would be willing to pay $\$ 7.72$ (in 2009 dollars) on each trip to increase the bag limit for king mackerel by one fish. This is close to our $\$ 12$ estimate of angler WTP on charter and private boat trips to open the king mackerel season.

Whitehead (2006) estimated that anglers fishing from the shore, private boats, party boats, or charter boats in the southeastern U.S. were willing to pay $\$ 3.29$ (in 2009 dollars) on average for an annual permit that would increase the king mackerel bag limit by 1 fish on every trip during the year. This is considerably lower than the WTP estimate from our study and the estimate from Whitehead et al. (2011) for king mackerel bag limit change on charter and private boat trips. The estimates are difficult to compare, however, because the Whitehead (2006) estimate is an annual payment for a bag limit change on every trip, whereas our estimate and the Whitehead et al. (2011) estimate refer to the WTP for a bag limit change on one trip.

The Whitehead et al. (2011) charter fishing study also produced a WTP estimate for a one-fish change in the "snapper-grouper" bag limit of $\$ 10.30$ (in 2009 dollars). This is higher than the average WTP per aggregate snapper of $\$ 2.2(\$ 11 / 5)$ going from a 5 fish to a 10 fish bag limit on charter trips in our study. Our estimate of angler WTP of \$6 per fish for changes in the grouper bag limit is still lower, but closer to the Whitehead et al. (2011) estimate. Indeed, the Whitehead et al. (2006) estimate of $\$ 10.30$ per snappergrouper bag limit unit is just outside our confidence interval of $\$ 4$ and $\$ 9$ per grouper bag limit unit. It could be that some snappers are seen as being relatively more valuable than grouper which may have contributed to the relatively higher estimate in the broader

given trip. The former measures the value of a change in the (average) number of fish taken home, whereas the latter measures the value of a change in the allowable number of fish that can be taken home. For example, an angler may not be willing to pay much for an increase in the bag limit if they do not expect to catch the limit. category used by Whitehead et al. (2006).

Finally, our study compared anglers' preferences across different modes of fishing: private or charter boat. We find that the amount anglers are willing to pay for changes in dolphinfish, aggregate snapper, and king mackerel regulations does not depend on the mode of fishing. This is not the case, however, for red snapper and grouper.

Anglers on charter boat trips are willing to pay to open the red snapper season, but anglers on private boat trips are not, regardless of the bag limit. That said, in the years studied, red snapper was not often caught by private-boat anglers off the North Carolina through Georgia coast, hence the finding of insignificance might reflect inapplicability of the choice situation, rather than underlying preferences.

In contrast, the WTP of anglers fishing on charter boats increases linearly in the grouper bag limits, whereas anglers fishing on private boats are willing to pay to open the season, but no further amounts for higher bag limits. This does not support the hypothesis that anglers' preferences are the same between the two fishing modes.

We note, though, that for groupers our experiment used increments of two fish. Anglers fishing from private boats are willing to pay nearly twice as much (\$24) as those fishing from charter boats $(\$ 12)$ to open the grouper season with a 2-fish bag limit. It may be that anglers fishing from charter boats expect to catch more than two grouper and are, therefore, willing to pay more for each subsequent fish beyond two. Private anglers may not expect to catch more than two fish and so do not show a WTP beyond two fish. More research is needed regarding the implications of angler catch expectations for the value of regulations in different modes of fishing.

\section{Acknowledgments}

We thank NOAA's Marine Recreational Information Program and the States of North Carolina, South Carolina, and Georgia for their cooperation in implementing the economic sur- 
veys. Sabrina Lovell at the NMFS Office of Science and Technology also helped us coordinate the surveys and provided valuable comments along the way. Most importantly, however, we would like to thank the anglers who completed the surveys and the charter captains who helped us develop the survey instruments.

\section{Literature Cited}

Aizaki, H. 2015. mded: Measuring the difference between two empirical distributions. $\mathrm{R}$ package version 0.1-2. (https://CRAN.R-project.org/package $=$ mded $)$

Anderson, L. E., and S. T. Lee. 2013. Untangling the recreational value of wild and hatchery salmon. Mar. Res. Econ. 28:175-197. (doi: https://doi.org/10.5950/0738-1360-28.2.175). and P S. Levin. 2013. Costs of delaying conservation: regulations and the recreational values of exploited and co-occurring species. Land Econ. 89:371-385. (doi: https://doi.org/10.3368/ le.89.2.371).

Bockstael, N. E., and K. E. McConnell. 2007. Environmental and resource valuation with revealed preferences: a theoretical guide to empirical models. Springer, Dordrecht, Netherl., 392 p.

Carter, D. W., and C. Liese. 2012. The economic value of catching and keeping or releasing saltwater sport fish in the southeast USA. N. Am. J. Fish. Manage. 32:613-625. (doi: https://doi.org/10.1080/02755947.2012.6759 43).

Croissant, Y. 2013. mlogit: multinomial logit model. R package version 0.2-4. (https:// CRAN.R-project.org/package $=$ mlogit $)$.

Ferrini, S., and R. Scarpa. 2007. Designs with a priori information for nonmarket valuation with choice experiments: a Monte Carlo study. J. Environ. Econ. Manage. 53:342-336. (doi: https://doi.org/10.1016/j. jeem.2006.10.007)
Haab, T. C., and K. E. McConnell. 2002. Valuing environmental and natural resources: the econometrics of non-market valuation. Edward Elgar Publ., Northampton, Mass., 352

Hole, A. R. 2007. A comparison of approaches to estimating confidence intervals for willingness to pay measures. Health Econ. 16:827840. (doi: https://doi.org/10.1002/hec.1197).

Johnston, R. J., M. H. Ranson, E. Y. Besedin, and E. C. Helm. 2006. What determines willingness to pay per fish? A meta-analysis of recreational fishing values. Mar. Resour. Econ. 21:1-32. (doi: https://doi.org/10.1086/ mre.21.1.42629492).

Krinsky, I., and A. L. Robb. 1986. On approximating the statistical properties of elasticities. Rev. Econ. Stat. 68:715-719. (doi: https://doi. org/10.2307/1924536).

Kuhfeld, W. F. 2010. Marketing research methods in SAS: experimental design, choice, conjoint, and graphical techniques, SAS 9.2 Ed. MR-201, SAS Inst., Inc., Cary, N.C.

Layton, D. F. 2001. Alternative approaches for modeling concave willingness to pay functions in conjoint valuation. Am. J. Agric. Econ. 83:1,314-1,320. (doi: https://doi.org/ $10.1111 / 0002-9092.00284)$ and G. Brown. 2000. Heterogeneous preferences regarding global climate change. Rev. Econ. Stat. 82:616-624. (doi: https://doi.org/10.1162/003465300559091).

Lew, D. K., and D. M. Larson. 2012. Economic values for saltwater sport fishing in Alaska: a stated preference analysis. N. Am. J. Fish. Manage. 32:745-759. (doi: https://doi.org/10 1080/02755947.2012.681012).

and 2014. Is a fish

in hand worth two in the sea? Evidence from a stated preference study. Fish. Res. 157:124-135. (doi: https://doi.org/10.1016/j. fishres.2014.04.005). and 2015. Stated preferences for size and bag limits of Alaska charter boat anglers. Mar. Pol. 61:66-76. (doi: https://doi.org/10.1016/j. marpol.2015.07.007).

McFadden, D. 1974. Conditional logit analysis of qualitative choice behavior. In P. Zarembka
(Editor), Frontiers in Econometrics, p. 105142. Acad. Press, N.Y.

Oh, C. O., R. Ditton, B. Gentner, and R. Reichers. 2005. A stated preference choice approach to understanding angler preferences for management options. Hum. Dim. Wildl. 10:173-186. (doi: https://doi. org/10.1080/10871200591003427).

Poe, G. L., K. L. Giraud, and J. B. Loomis. 2005. Computational methods for measuring the difference of empirical distributions. Am. J. Agric. Econ. 87: 353-365. (doi: https://doi. org/10.1111/j.1467-8276.2005.00727.x).

Poor, P. J., and M. Breece. 2006. The contingent behavior of charter fishing participants on the Chesapeake Bay: welfare estimates associated with water quality improvements. J. Environ. Plann. Manage. 49:265-278. (doi: https://doi.org/10.1080/0964056050050 8064).

R Core Team. 2016. R: A language and environment for statistical computing. R Foundation for Statistical Computing, Vienna, Austria. (https://www.R-project.org/).

Siikamäki, J., and D. F. Layton. 2007. Discrete choice survey experiments: a comparison using flexible methods. J. Environ. Econ. Manage. 53:122-139. (doi: https://doi. org/10.1016/j.jeem.2006.04.003).

Swait, J., and J. Louviere. 1993. The role of the scale parameter in the estimation and comparison of multinomial logit models. J. Market. Res. 30:305-314. (doi: https://doi. org/10.2307/3172883).

Train, K. 2009. Discrete choice methods with simulation. Camb. Univ. Press, N.Y., 342 p.

Whitehead, J. C. 2006. A comparison of contingent valuation method and random utility model estimates of the value of avoiding reductions in king mackerel bag limits. Applied Econ. 38:1,725-1,736. (doi: https://doi. org/10.1080/00036840500427130).

C. F. Dumas, C. E. Landry, and

J. Herstine. 2011. Valuing bag limits in the North Carolina charter boat fishery with combined revealed and stated preference data. Mar. Res. Econ. 26:233-241. (doi: https://doi.org/10.5950/0738-1360-26.3.233). 